\title{
Influence Factors Analysis of Provincial Divorce Rate Spatial Distribution in China
}

\author{
Liyun Su (D), Changhai Liang, Xiaohe Yang, and Yang Liu \\ School of Science, Chongqing University of Technology, Chongqing 400054, China \\ Correspondence should be addressed to Liyun Su; cloudhopping@163.com
}

Received 17 May 2018; Accepted 9 July 2018; Published 16 July 2018

Academic Editor: Allan C. Peterson

Copyright (C) 2018 Liyun Su et al. This is an open access article distributed under the Creative Commons Attribution License, which permits unrestricted use, distribution, and reproduction in any medium, provided the original work is properly cited.

Divorce is the primary factor affecting the harmony and stability of the family and society. This paper uses spatial statistics to analyze the potential social causes of influencing the spatial distribution of divorce rates in various provinces of China. Firstly, the factors of social influence, family cohesion, and ethnic customs are constructed by factor analysis, then the spatial interaction effect of divorce rate in each province is brought into the model, and the spatial regression analysis of these three factors is carried out. The results show that social influence, especially the tertiary industry share of GDP, has a significant influence on the divorce rate, family cohesion has a distinct negative effect on the divorce rate, and ethnic customs have a noteworthy impact on the divorce rate. It is reflected in the high divorce rate of the majority of ethnic minority population, while, in the spatial data processing, the factor spatial lag model (FSLM) is better than the ordinary least square (OLS) regression model.

\section{Introduction}

Marriage as a form of family, whether traditional or modern, has a special significance to human society, but divorce is an important factor that affects the harmony and stability of family and society. Since the 1970s, with the improvement of China's economic level, urbanization process, and the improvement of personal quality of life, the divorce rate has obviously increased. Xu A (1991) and others [1] believed that the divorce rate in China will rise and will keep rising for a long time. Fu H (2008) and others [2] predicted that the level of divorce in China will show a slow upward trend in the 21st century. Xia Y (2008) and others [3] believed that the divorce situation in China is not optimistic in the future, and the rising divorce rate is a big trend. According to the ministry of civil affairs, in 2013, there were 3.5 million couples in China who registered for divorce according to law, and the amount has an increase of $12.8 \%$ over the previous year. In 2014, there were 3.637 million couples. There were 3841,000 couples in 2015. Chinese divorce rate has been rising for 13 consecutive years since 2003. In December 2015, Du W, an official of the Supreme People's Court, said in an interview with the media that there were about 1.6 million cases of marriage and family in 2014, of which more than 1.2 million were divorce cases. It can be seen that, regardless of the statistics, the divorce rate is high, and the issue of divorce has become a hot issue in the current society. Su L (2015) and others [4] in an analysis of the spatial aggregation and temporal and spatial pattern evolution of divorce rates in various provinces in China pointed out that the law of spatiotemporal evolution of divorce rates in China has strong regional and space-time characteristics; overall, the divorce rate of provinces exists in the phenomenon of high-high and low-low forms. An article by Du Anna in "Guangzhou Daily" called "The Divorce Rate Space Distribution Research in our Country, Guangdong Province Has the Low Rate of Divorcing" was very influential, causing newspaper and network media coverage, and has been widely reported and reproduced in the "Southern Network", "Shenzhen News Network", "sina.com", and so forth, but this paper has not studied the spatial distribution characteristics of divorce rate and the potential social causes behind the phenomenon of aggregation.

Foreign research on marital status, marital quality, and the factors of divorce rate has been relatively mature system, but most of the foreign empirical studies are at a certain time and a single area which lack cross-regional and crosscultural research. Studies of divorce rate differences in foreign countries were active in the 1970s, which has put forward 
three representative interpretations, that is, social aggregation theory (K.D. Breault and A.J. Kposowa, 1987) [5]; marriage legal theory (Nakonezny et al., 1995) [6]; and economic and social structure (Glick, Petal, 1986; Katherine, T. et al., 1989) $[7,8]$. From the results of this study, social influence and economic and family structure can be indexes as the main control variable is introduced into the model; then we can study the effect of social comprehensive index on the divorce rate. And domestic study of marital problems is still immature and imperfect, mostly focusing on the analysis of consequences of divorce trend, reason for divorce proceedings, and the results of divorce; especially the social cause of the divorce problem analysis mostly stays in the theoretical level. They used parts of data to build a simple model that lacks good empirical exploration to analyze the influence factors of the divorce rate. Zhang J (2008) [9] established a linear regression metrological model and found that the development of economic level is related to the divorce rate. In the study of the regional difference analysis of the divorce rate in China by Xu A (2002) [10], a total of 11 variables, such as the amount of foreign investment, were selected to analyze the differences. And she found that the composite family structure factors, such as family population quantity, had the greatest impact on the change of divorce rate and the social cohesion factor, which was composed of the proportion of urban population, was also significantly correlated with the divorce rate. Gao M (2011) [11] studied the village panel data from 2003 to 2009 in China and found that the outside employment has a significant influence on the rural divorce rate and the regional influence of different development levels is different. The characteristics of the high divorce rate in Xinjiang Uygur areas and the analysis of its causes show that the divorce rate of Xinjiang Uygur in the past 20 years is different from that in other parts of the country and has not shown an upward trend, but has declined steadily in the past 20 years (Xu A, 2001) [12]. It can be seen from domestic and international studies that the study on divorce rate ignores the spatial dependence of divorce data in different regions.

At present, the research on spatial regression model has a lot of, mainly using spatial regression model of unbalanced regional population, fertility rates, economic development, real estate, energy consumption and so on, which focus on the model fitting, parameter estimation, and test. Liu Hua (2014) [13] and others based on the spatial data exploration technology analyzed the spatial difference and spatial clustering characteristics of the sex ratio of Chinese rural birth population and used the spatial geographical weighting model to measure the influence of various social factors on the sex ratio of rural population in China. Some scholars also use spatial data analysis methods to study the spatial distribution and evolution mechanism of China's low fertility, and they selected nearly 10 years of relevant data. The influence factors of low fertility rate were estimated by using spatial geographical weighting model, and the spatial difference was also studied (Tan Y, Yong M, 2014) [14]. In general, no one uses spatial statistical model to study the influence factors of the divorce rate; the use of the space regression model to explore the factors influencing the spatial distribution of potential social divorce rate is meaningful under the background of the divorce rate of spatial aggregation pattern evolution law.

This paper uses factor analysis to explore the correlation of the variable that influences the divorce rate to construct the impact factor of divorce rate, and using spatial weight matrix represents provinces adjacent relations to realize the provinces spatial interaction effect of divorce rate. On the basis of the traditional regression model, the spatial lag model and spatial error model are introduced to analyze the influencing factors of divorce rate in various provinces of China, and the results are compared with those of ordinary least square regression.

\section{Model Method, Data Description, and Variable Selection}

2.1. Spatial Regression Model (SRM). The common spatial autoregressive model mainly includes spatial lag model (SLM) and spatial error model (SEM). Anselin (1988) [15] considered the spatial correlation between explained variables and explanatory variables; a general formula of the spatial regression model is given.

$$
\begin{aligned}
& \mathrm{Y}=\rho \mathrm{W}_{1} \mathrm{Y}+\mathrm{X} \beta+\mu, \\
& \mu=\lambda \mathrm{W}_{2} \mu+\varepsilon, \varepsilon \sim \mathrm{N}\left(0, \sigma^{2} \mathrm{I}_{\mathrm{n}}\right)
\end{aligned}
$$

where $\mathrm{Y}$ is the interpreted variable, which is $\mathrm{n} \times 1$ order vector; $\mathrm{X}$ is the explanatory variable, which is a $\mathrm{n} \times \mathrm{k}$ matrix; $\mu$ is the error term in space regression; $\varepsilon$ is white noise; $\rho$ and $\lambda$ are spatial correlation parameter; $\mathrm{W}_{1}, \mathrm{~W}_{2}$ are the exogenous space weight matrix established according to the adjacent relation.

\subsubsection{Spatial Lag Model (SLM)}

$$
\mathrm{Y}=\rho \mathrm{W}_{1} \mathrm{Y}+\mathrm{X} \beta+\varepsilon, \quad \varepsilon \sim \mathrm{N}\left(0, \sigma^{2} \mathrm{I}_{\mathrm{n}}\right)
$$

In the formula (1), make $\mathrm{W}_{1} \mathrm{Y}=0$, and get the spatial lag model; parameter $\beta$ reflects the influence of independent variable on the dependent variable; the changes of $\mathrm{Y}$ are additionally associated with its neighboring unit's explained variable and also associated with explanatory variables $\mathrm{X}$; the spatial lag dependent variable $\mathrm{W}_{1} \mathrm{Y}$ is an endogenous variable and reflects the spatial interaction of regional action.

\subsubsection{Spatial Error Model (SEM)}

$$
\mathrm{Y}=\mathrm{X} \beta+\mu, \quad \mu=\lambda \mathrm{W}_{2} \mu+\varepsilon, \varepsilon \sim \mathrm{N}\left(0, \sigma^{2} \mathrm{I}_{\mathrm{n}}\right)
$$

In formula (1), make $\mathrm{W}_{1}=0$, and get the spatial error model; this model is also commonly used in space form of $\operatorname{AR}(1) ; \lambda$ is $n \times 1$ order's cross section of the variable vector space error coefficient; $\mu$ is random error vector; $\varepsilon$ is for normal distribution random error vector. Parameter $\beta$ reflects the influence of the independent variable $\mathrm{X}$ on the dependent variable $\mathrm{Y}$, and parameter $\lambda$ measures the spatial 
dependence of the sample observation value, namely, the influence direction and degree of the observed value in the neighboring region. Because of the spatial dependence of the perturbation error term, the influence of the error impact of the dependent variable on the observed value of the region is measured. This model is usually used to reflect the effect of regional spilt on random errors, rather than from the system part of the model, when the interactions have differences because of the relative position of the local area.

\subsubsection{Ordinary Least-Squares (OLS) Regression}

$$
\mathrm{Y}=\mathrm{X} \beta+\varepsilon, \quad \varepsilon \sim \mathrm{N}\left(0, \sigma^{2} \mathrm{I}_{\mathrm{n}}\right)
$$

In formula (1), making $\rho=\lambda=0$, the ordinary leastsquares regression is obtained.

In view of the endogeneity of the independent variables in spatial regression model, the estimation of SLM and SEM, Anselin (1988) [15], uses the method of maximum likelihood, which makes the estimation unbiased and effective. When testing spatial correlation of spatial data and the selection of specific spatial regression model, Moran's I statistics are generally selected, i.e., two-Lagrangian multipliers with Lagrange multiplier error (LMERR), Lagrange multiplier lag (LMLAG), and the robust of Lagrange multiplier error and lag (R-LMERR, R-LMLAG) forms. Since it is impossible to infer the existence of spatial dependence in SLM and SEM based on prior experience, Anselin and others (1996) [16] give the selection criteria for SLM and SEM in practical application: if LMLAG is more statistically significant than LMERR in the test of spatial dependence and R-LMLAG is significant and R-LMERR is not significant, it can be concluded that the appropriate model is SLM; Conversely, if LMERR is statistically more significant than LMLAG and RLMERR is significant and R-LMLAG is not significant, it can be concluded that SEM is the appropriate model. I would like to add to that commonly used inspection criteria including goodness of fit $\mathrm{R}^{2}$ test, Log likelihood ( $\left.\log \mathrm{L}\right)$, Likelihood Ratio(LR), Akaike information criterion (AIC), and Schwartz criterion(SC). The bigger LogL is, the smaller AIC and SC are, and the better the model fits.

To verify the rationality of the final regression model, residual test is an indispensable step. Firstly, we examine the normality of residuals by the residual plot and normal Q-Q plot; Shapiro and Wilk (1965) [17] proposed ShapiroWilk normality Test, which determines whether residuals are distributed from a normal distribution. Then, under the assumption that residuals satisfy normality, random test of residual can be used to test random residual randomness by Mood's run-test method proposed in 1940. If residuals do not satisfy normality and randomness, Jia L (2008) [18] proposed that methods can be used to deal with different distributions of residual in complex regression models, then deal with residuals, and optimize regression equations further.

2.2. Data Declaration. The research subjects included 31 provinces, municipalities directly under the central government and autonomous regions in China, except Hong Kong,
Macao, and Taiwan. In the study of social indicators such as divorce rates, this paper uses sectional data for spatial analysis and does not involve temporal analysis. The divorce rate is the ratio of the number of divorces registered in the unit time to the number of marriages registered in the unit time. The data of divorce registration and marriage registration in all provinces of China are from the statistical data of the national bureau of statistics of the People's Republic of China in 2010 [19]. Considering the availability and completeness of relevant data, the data of all variables in this paper are from the sixth national census data in 2010 .

2.3. Variable Selection. With the speeding up of urbanization progress, the open personal lifestyle separating the people from the traditional social life and large population flow will weaken the social convergence, which in turn reduce the intervention of the social influence of personal life and increase the possibility of divorce. In traditional culture, the stability of marriage can be maintained by family factors, such as the cultural level of family members. Studies have shown that there is a certain relationship between the number of people with low education level and the divorce rate; the higher the illiteracy rate, the lower the divorce rate (Wang S, 2011) [20]. In real life, the influence of the cultural level on the family is often ignored. Urbanization level and population flow coefficient are also related to the divorce rate (Xu A, 2002) [10]. Besides, ethnic minority residence has obvious regional characteristics, and their lifestyle and marriage customs also influence marriage (Xu A, 2001) [12]. In addition, one of the most attractive variables is Chinese fertility policies, and its impact on divorce rate is also an interesting topic, due to the lack of data from different regions of the country. Later, we will discuss the impact of the changes in Chinese fertility policies on the divorce rate separately. In these three articles, as well as considering the universality and rationality of the variables, this paper adopts the tertiary industry share of GDP, the population flow coefficient, consumption level of residents, per capita gross domestic product, proportion of higher education population, proportion of urban population, illiteracy rate, the birth rate, family population quantity, population raising coefficient, number of surviving children of women aged 1564 years, and proportion of ethnic minorities, a total of 12 indicators to explain the effect on the spatial distribution of divorce rate (shown in Table 1).

\section{Constructing Spatial Statistical Model}

\subsection{Construction of Influencing Factors}

3.1.1. Correlation Analysis. Firstly, explore the correlation between the 12 explanatory variables and the divorce rate $(\mathrm{Y})$ and explanatory variables (shown in Table 2).

Seen from Table 2, the number of explanatory variables is large and involves various aspects. It can be seen that there is a strong correlation between explanatory variables. There is a positive correlation between the proportion of the urban population $\left(\mathrm{X}_{6}\right)$ and the tertiary industry share of GDP $\left(\mathrm{X}_{1}\right)$, population flow coefficient $\left(\mathrm{X}_{2}\right)$, consumption level of 
TABLE 1: Variable interpretation.

\begin{tabular}{lc}
\hline variable & unit \\
\hline The tertiary industry share of GDP. $\left(X_{1}\right)$ & $(\%)$ \\
Population flow coefficient $\left(X_{2}\right)$ & $(\%)$ \\
Consumption level of residents $\left(X_{3}\right)$ & $($ yuan $)$ \\
Per capita gross domestic product $\left(X_{4}\right)$ & $($ yuan $)$ \\
Proportion of higher education population $\left(X_{5}\right)$ & $(\%)$ \\
The proportion of the urban population $\left(X_{6}\right)$ & $(\%)$ \\
Illiteracy rate $\left(X_{7}\right)$ & $(\%)$ \\
The birth rate $\left(X_{8}\right)$ & $(\%)$ \\
Family population quantity $\left(X_{9}\right)$ & $($ people) \\
Population raising coefficient $\left(X_{10}\right)$ & $(\%)$ \\
Number of surviving children of women aged 15-64 & $($ people) \\
years $\left(X_{11}\right)$ & $(\%)$ \\
Proportion of ethnic minorities $\left(X_{12}\right)\left(F_{3}\right)$ &
\end{tabular}

residents $\left(\mathrm{X}_{3}\right)$, per capita gross domestic product $\left(\mathrm{X}_{4}\right)$, and proportion of higher education population $\left(\mathrm{X}_{5}\right)$ which are positively correlated, with correlation coefficients of 0.472 , $0.538,0.906,0.922,0.941$, and 0.912 , respectively, while the proportion of the urban population $\left(\mathrm{X}_{6}\right)$ is negatively correlated with the remaining explanatory variables. The correlation between proportion of ethnic minorities $\left(\mathrm{X}_{12}\right)$ and other explanatory variables is relatively low; in addition, the explanatory variables were strongly correlated with other explanatory variables, respectively, for the proportion of the urban population $\left(\mathrm{X}_{6}\right)$ and the number of surviving children of women aged 15-64 years $\left(\mathrm{X}_{11}\right)$ with correlation coefficients of 0.476 and -0.659 .

3.1.2. Factor Analysis. Considering the selected interpretation variables, only the proportion of ethnic minorities relates to ethnic customs influencing factor, and the correlation is low. This section alone is taking it out, and only 11 variables are analyzed. Firstly, KMO test and Bartlett test were used to discuss the applicability of factor analysis (shown in Table 3).

According to the Bartlett test value in Table 3, the $P$ value is approximately equal to 0 , which obviously rejected the original hypothesis of independent variables, and it can be concluded that there is an obvious correlation between each variable. And KMO test statistic is 0.860 , far greater than 0.7 , which indicates that the overlapping degree of information between each variable is relatively high, which ensures that explanatory variables have clear explanation and that it is reasonable to use factor analysis to reduce the dimensionality of variables (the results shown in Table 4).

The factor analysis results from Table 4 show the following.

(1) The first six independent variables $\mathrm{X}_{1}, \mathrm{X}_{2}, \mathrm{X}_{3}, \mathrm{X}_{4}, \mathrm{X}_{5}$, $\mathrm{X}_{6}$, that is, compound factor 1 are named social influence $\left(\mathrm{F}_{1}\right)$ whose characteristic value is 5.147 and the explanation for the overall quantity is $46.788 \%$.

(2) The remaining 5 independent variables $X_{7}, X_{8}, X_{9}$, $\mathrm{X}_{10}, \mathrm{X}_{11}$, that is, compound factor 2 are named family

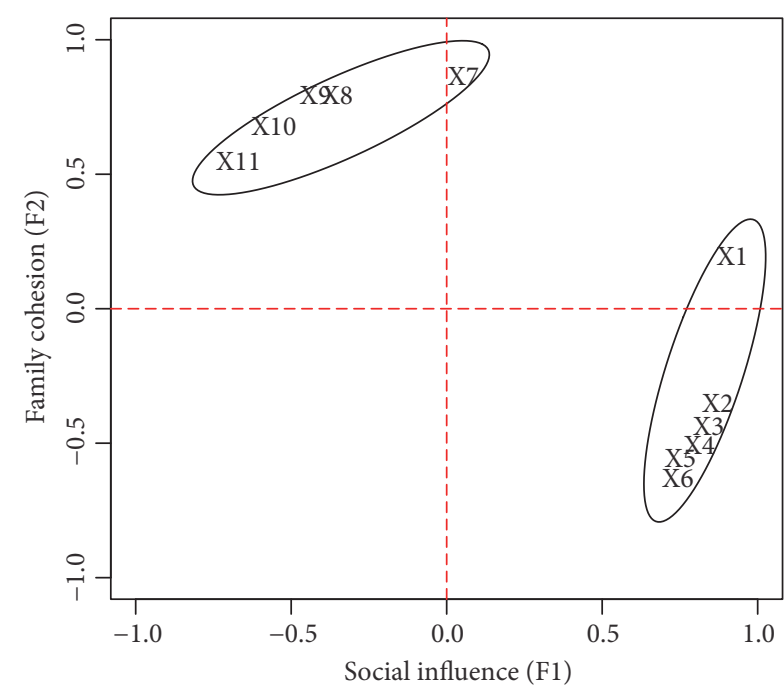

FIGURE 1: Factor loading diagram.

cohesion $\left(\mathrm{F}_{2}\right)$ whose characteristic value is 4.083 and the interpretation of the overall level is $37.199 \%$.

(3) The cumulative interpretation ratio is $83.908 \%$ and explains the total amount of information about $84 \%$, which indicates that the information loss is small, and the explanatory ability of the common factor to each variable is relatively strong, which indicates the applicability of factor analysis to a certain extent. Moreover, it can be seen from the factor loading diagram (Figure 1) that it is reasonable to propose two factors. Social influence $\left(F_{1}\right)$ is mainly concentrated in the fourth quadrant, and family cohesion $\left(\mathrm{F}_{2}\right)$ is mainly concentrated in the second quadrant. The factor scoring function of social influence $\left(\mathrm{F}_{1}\right)$ and family cohesion $\left(\mathrm{F}_{2}\right)$ can be obtained by the following formula:

$$
\begin{aligned}
\mathrm{F}_{1}= & 0.917 \mathrm{x}_{1}+0.87 \mathrm{x}_{2}+0.841 \mathrm{x}_{3}+0.811 \mathrm{x}_{4}+0.75 \mathrm{x}_{5} \\
& +0.742 \mathrm{x}_{6}+0.052 \mathrm{x}_{7}-0.353 \mathrm{x}_{8}-0.423 \mathrm{x}_{9} \\
& -0.559 \mathrm{x}_{10}-0.672 \mathrm{x}_{11} \\
\mathrm{~F}_{2}= & 0.195 \mathrm{x}_{1}-0.351 \mathrm{x}_{2}-0.436 \mathrm{x}_{3}-0.509 \mathrm{x}_{4}-0.556 \mathrm{x}_{5} \\
& -0.632 \mathrm{x}_{6}+0.863 \mathrm{x}_{7}+0.793 \mathrm{x}_{8}+0.793 \mathrm{x}_{9} \\
& +0.677 \mathrm{x}_{10}+0.55 \mathrm{x}_{11}
\end{aligned}
$$

3.2. Establishment of Spatial Statistical Model. Social influence $\left(\mathrm{F}_{1}\right)$ and family cohesion $\left(\mathrm{F}_{2}\right)$ and minority customs $\left(\mathrm{F}_{3}\right)$ (also called proportion of ethnic minorities $\mathrm{X}_{12}$ ) in the regression model explore the influence of each factor on the divorce rate. Considering that joining ethnic populations could make their convergence, multicollinearity of family and social influence exists and variance inflation factor is used to explore the question of whether or not to have collinearity (shown in Table 5).

It can be seen from Table 5 that the variance expansion factor of each variable is very low, with an average value of 1.889, which is far less than 10, indicating that the multicollinearity between variables is small, which can be 
TABle 2: Correlation Coefficient.

\begin{tabular}{|c|c|c|c|c|c|c|c|c|c|c|c|c|c|}
\hline & $Y$ & $X_{1}$ & $X_{2}$ & $X_{3}$ & $X_{4}$ & $X_{5}$ & $X_{6}$ & $X_{7}$ & $X_{8}$ & $X_{9}$ & $X_{10}$ & $X_{11}$ & $X_{12}$ \\
\hline Y & 1 & & & & & & & & & & & & \\
\hline$X_{1}$ & 0.086 & 1 & & & & & & & & & & & \\
\hline$X_{2}$ & 0.321 & $.698 * *$ & 1 & & & & & & & & & & \\
\hline$X_{3}$ & 0.353 & $.648 * *$ & $.931 * *$ & 1 & . & . & & & & & & & \\
\hline$X_{4}$ & $.397 *$ & $.580 * *$ & $.898 * *$ & $.924 * *$ & 1 & & . & - & & & & & \\
\hline$X_{5}$ & $.430 *$ & $.611 * *$ & $.833 * *$ & $.839 * *$ & $.868 * *$ & 1 & & - & & & & & \\
\hline$X_{6}$ & $.472 * *$ & $.538 * *$ & $.906 * *$ & $.922 * *$ & $.941 * *$ & $.912 * *$ & 1 & & & & & & \\
\hline$X_{7}$ & -0.286 & 0.153 & -0.337 & $-.375 *$ & $-.393 *$ & $-.528 * *$ & $-.561 * *$ & 1 & & & & & \\
\hline$X_{8}$ & $-.619 * *$ & -0.217 & $-.495 * *$ & $-.600 * *$ & $-.639 * *$ & $-.647 * *$ & $-.703 * *$ & $.499 * *$ & 1 & & & & \\
\hline$X_{9}$ & $-.626 * *$ & -0.262 & $-.675 * *$ & $-.719 * *$ & $-.733 * *$ & $-.692 * *$ & $-.798 * *$ & $.617 * *$ & $.808 * *$ & 1 & & & \\
\hline$X_{10}$ & $-.551 * *$ & -0.348 & $-.671 * *$ & $-.683 * *$ & $-.789 * *$ & $-.796 * *$ & $-.810 * *$ & $.456 * *$ & $.762 * *$ & $.674 * *$ & 1 & & \\
\hline$X_{11}$ & $-.659 * *$ & $-.479 * *$ & $-.649 * *$ & $-.738 * *$ & $-.818 * *$ & $-.787 * *$ & $-.791 * *$ & 0.269 & $.791 * *$ & $.670 * *$ & $.864 * *$ & 1 & \\
\hline$X_{12}$ & -0.068 & 0.098 & -0.253 & -0.396 & $-.387 *$ & $-.450 *$ & $-.504 * *$ & $.718 * *$ & $.634 * *$ & $.571 * *$ & $.456 * *$ & 0.333 & 1 \\
\hline
\end{tabular}

Note. *. Significantly correlated at the level of 0.05 (bilateral), **. Significant correlation was found on the.01 level (bilateral).

TABLE 3: KMO statistics and Bartlett test.

\begin{tabular}{lcc}
\hline Kaiser-Meyer-Olkin statistics & & 0.860 \\
& The approximate chi-square & 441.326 \\
Bartlett Sphericity test & Degrees of freedom & 55 \\
& P values & 0.000 \\
\hline
\end{tabular}

TABLE 4: Factor analysis results of variables.

\begin{tabular}{lcc}
\hline variables & Factor loading & Factor2 \\
\hline$X_{1}$ & 0.917 & 0.195 \\
$X_{2}$ & 0.870 & -0.351 \\
$X_{3}$ & 0.841 & -0.436 \\
$X_{4}$ & 0.811 & -0.509 \\
$X_{5}$ & 0.75 & -0.556 \\
$X_{6}$ & 0.742 & -0.632 \\
$X_{7}$ & 0.052 & 0.863 \\
$X_{8}$ & -0.353 & 0.793 \\
$X_{9}$ & -0.423 & 0.793 \\
$X_{10}$ & -0.559 & 0.677 \\
$X_{11}$ & -0.672 & 0.55 \\
\hline New naming factor & Social influence (F1) & Family cohesion (F2) \\
The eigenvalue & 5.147 & 4.083 \\
Factor interpretation ratio (\%) & 46.788 & 37.119 \\
Cumulative interpretation ratio (\%) & 46.788 & 83.908 \\
\hline
\end{tabular}

used to construct the regression model. The spatial regression model is based on the traditional regression model, because the space variable does not satisfy the independence of the objects in the classical statistical observation; in many cases the traditional regression analysis will lead to wrong conclusions. Next, the spatial interaction effects between provinces and cities are realized through the spatial weighting matrix, and the model is included. The spatial lag model (FSLM) and the factor space error model (FSEM) are constructed by integrating factor analysis and spatial regression model (FSEM) as follows.

Model I: Factor Spatial Lag Model (FSLM).

$$
\begin{aligned}
& \mathrm{Y}=\rho \mathrm{W}_{1} \mathrm{Y}+\beta_{0}+\beta_{1} \mathrm{~F}_{1}+\beta_{2} \mathrm{~F}_{2}+\beta_{3} \mathrm{~F}_{3}+ \varepsilon, \\
& \\
& \varepsilon \sim \mathrm{N}\left(0, \sigma^{2} \mathrm{I}\right)
\end{aligned}
$$


TABLE 5: Variance expansion factor of three variables.

\begin{tabular}{lc}
\hline variables & Variance expansion factor \\
\hline Social influence $\left(F_{1}\right)$ & 1 \\
Family cohesion $\left(F_{2}\right)$ & 2.336 \\
Minority customs $\left(F_{3}\right)$ & 2.336 \\
Average variance expansion Factor & 1.889 \\
\hline
\end{tabular}

Model II: Factor Spatial Error Model (FSEM).

$$
\begin{aligned}
& \mathrm{Y}=\beta_{0}+\beta_{1} \mathrm{~F}_{1}+\beta_{2} \mathrm{~F}_{2}+\beta_{3} \mathrm{~F}_{3}+\mu \\
& \mu=\lambda \mathrm{W}_{2} \mu+\varepsilon, \quad \varepsilon \sim \mathrm{N}\left(0, \sigma^{2} \mathrm{I}\right)
\end{aligned}
$$

where $\mathrm{F}_{1}, \mathrm{~F}_{2}, \mathrm{~F}_{3}$, respectively, represent

$$
\begin{aligned}
& \mathrm{F}_{1}=\alpha_{1} \mathrm{X}_{1}+\alpha_{2} \mathrm{X}_{2}+\ldots+\alpha_{11} \mathrm{X}_{11} \\
& \mathrm{~F}_{2}=\gamma_{1} \mathrm{X}_{1}+\gamma_{2} \mathrm{X}_{2}+\ldots+\gamma_{11} \mathrm{X}_{11} \\
& \mathrm{~F}_{3}=\mathrm{X}_{12}
\end{aligned}
$$

In formulas (7) and (8), Y represents the divorce rate; $\mathrm{F}_{1}$ represents the factor score function of social influence; $\mathrm{F}_{2}$ denotes the factor score function of family cohesion; $\mathrm{F}_{3}$ denotes the value of ethnic minority ratio, which is also named the national convention factor; $\mathrm{W}_{1}$ and $\mathrm{W}_{2}$ are the spatial weight matrix set according to the neighboring relationship; $\rho$ and $\lambda$ are the estimated parameters; $\rho$ reflects the direct path; $\lambda$ reflects the indirect path; $\mathrm{X}_{1} \ldots \mathrm{X}_{12}$ are the selected variables.

\section{Empirical Study on the Influencing Factors of Divorce Rate in China}

4.1. Determination of Spatial Weight Matrix. In this paper, the spatial distribution of the provinces in China is mainly considered, and the Rook proximity criterion is adopted to establish the spatial weight matrix, and the four neighboring relationships are directly adjacent to one city as the geographical center. Generally, all elements on the main diagonal in the first-order adjacency matrix are set to 0 , and the elements in other positions are adjacent to the adjacent standard: if two provinces are connected, the adjacency matrix element is 1; otherwise it is 0 . Considering that Hainan province does not have the neighboring provinces, we set Guangdong province adjacent to Hainan province and set it as 1 in the matrix. For example, Chongqing is adjacent to Sichuan and Guizhou, so the value of the corresponding position of the matrix is 1 . Chongqing is not adjacent to Beijing, so the value is 0 .

\subsection{OLS Regression and Spatial Regression of the Influencing Factors}

4.2.1. Ordinary Least-Squares (OLS) Regression. The divorce rate is a continuous variable between 0 and 1 , which is associated with three factors for traditional regression analysis. The average least-square (OLS) estimation is adopted, and the estimated results are shown in Table 6.
The regression results from Table 6 can be obtained, and the adjusted fitting degree is 0.6121 , which is not a good fitting result in statistical terms, but, in the practical application, some factors that really affect the divorce rate cannot simply look at a relatively high fitting value to get the results. The coefficient of family cohesion $\left(\mathrm{F}_{2}\right)$ and minority customs $\left(\mathrm{F}_{3}\right)$ passed the test with significance level of 0.05 , and the social influence $\left(\mathrm{F}_{1}\right)$ and constant term did not pass the significance test with significance level of 0.05 , while the constant term was close to 0 , and the constant term was set to 0 in the actual model. The error of the regression model normality test (Jarque-Bera test) $\mathrm{P}$ value is 0.7921 ; the error term for the normality of the original hypothesis is accepted. The $\mathrm{P}$ value of the heteroscedasticity test (Breusch-Pagan test) is 0.6768 , and the original hypothesis of homogeneity of variance is also accepted.

Model of residual error Moran's I statistics $\mathrm{P}$ value is 0.04230 , the test is passed with significance level of 0.05 , which indicates that there exists significant spatial correlation in ordinary least-squares regression model error, further indicating that obvious regional influence exists in our country's divorce problem. This also indicates that the nonindependence of each unit of the cross section data is ignored, and the deviation of the result will be caused by using the ordinary least-square estimation directly.

For spatial lag model of LMLAG and R-LMLAG test indicators, respectively, the test of 0.01 and 0.05 significant level is passed; we think the divorce rate of provinces can be affected by borders directly. However, the LMERR and RLMERR tests of the spatial error model are obviously unable to pass the significance test, which means that the divorce rate in each province is not derived from some unrecognized spatial clustering characteristics. According to the selection criteria, the factor spatial lag model is more applicable to explaining the spatial dependence of divorce rate.

4.2.2. Factor Spatial Regression Analysis. In order to further contrast and verify in the ordinary least-squares regression, factor spatial lag model is more suitable for explaining the results of the spatial distribution of the divorce rate. Next, the spatial interaction effect of divorce rate in each province is included in the model, and spatial regression is used to analyze the divorce rate. The fitting results are shown in Table 7.

Further comparing the applicability of FSLM and FSEM, we can compare the AIC and SCS of the model, according to the smaller the better selection criteria, FSLM is superior; and, from $\log \mathrm{L}$, it can be seen that the LogL of FSLM is -21.4, which is obviously greater than the LogL of FSEM. Synthetically, considering the spatial lag term, FSLM can better explain the spatial interaction effect of divorce rate in every province in China. According to formulas (5), (6), and (7) and formula (9), the expression of FSLM is obtained as the following formula:

$$
\begin{aligned}
\mathrm{Y}= & 0.6077 \mathrm{~W}_{1} \mathrm{Y}+0.0477-0.02215 \mathrm{X}_{1}+0.49307 \mathrm{X}_{2} \\
& +0.569379 \mathrm{X}_{3}+0.634 \mathrm{X}_{4}+0.66811 \mathrm{X}_{5} \\
& +0.739563 \mathrm{X}_{6}-0.81835 \mathrm{X}_{7}-0.82404 \mathrm{X}_{8}
\end{aligned}
$$


TABLE 6: OLS estimation results.

\begin{tabular}{|c|c|c|c|c|}
\hline & Regression coefficient & standard deviation & T statistic & $P$ values \\
\hline Constant & 8.39E-06 & 0.1119 & $7.50 \mathrm{E}-05$ & 1 \\
\hline$F_{1}$ & 0.2282 & 0.1137 & 2.0069 & 0.0549 \\
\hline$F_{2}$ & -1.1814 & 0.17378 & -6.7983 & 0 \\
\hline$F_{3}$ & 0.827 & 0.1738 & 4.7589 & 0.0001 \\
\hline$R^{2}$ & 0.6509 & $\log \mathrm{L}$ & -27.1647 & \\
\hline Adjusted $R^{2}$ & 0.6121 & AIC & 62.3293 & \\
\hline F value & 16.7821 & SC & 68.0653 & \\
\hline $\mathrm{J}$-B test & 2 & & 0.4662 & 0.7921 \\
\hline B-P test & 2 & & 1.5235 & 0.6768 \\
\hline Moran's I & 0.1524 & & 2.0306 & 0.0423 \\
\hline LMLAG & 1 & & 7.0266 & 0.008 \\
\hline R-LMLAG & 1 & & 6.364 & 0.01165 \\
\hline LMERR & 1 & & 1.4141 & 0.2344 \\
\hline R-LMERR & & & 0.7515 & 0.386 \\
\hline
\end{tabular}

TABLE 7: FSLM and FSEM of maximum likelihood (ML) estimation.

\begin{tabular}{|c|c|c|c|c|c|c|c|c|}
\hline & \multicolumn{4}{|c|}{ Factor spatial lag model (FSLM) } & \multicolumn{4}{|c|}{ Factor spatial error model (FSEM) } \\
\hline & $\begin{array}{l}\text { Regression } \\
\text { coefficient }\end{array}$ & $\begin{array}{c}\text { standard } \\
\text { deviation }\end{array}$ & $\begin{array}{c}\mathrm{Z} \\
\text { statistics }\end{array}$ & $\begin{array}{c}\mathrm{P} \\
\text { values }\end{array}$ & $\begin{array}{l}\text { Regression } \\
\text { coefficient }\end{array}$ & $\begin{array}{l}\text { standard } \\
\text { deviation }\end{array}$ & $\begin{array}{c}\mathrm{Z} \\
\text { statistics }\end{array}$ & $\begin{array}{c}\mathrm{P} \\
\text { values }\end{array}$ \\
\hline Constant & 0.0477 & 0.0823 & 0.5803 & 0.5617 & 0.1139 & 0.3521 & 0.3234 & 0.7464 \\
\hline$F_{1}$ & 0.1798 & 0.0844 & 2.1294 & 0.033 & 0.2437 & 0.1024 & 2.3798 & 0.0173 \\
\hline$F_{2}$ & -0.9591 & 0.1381 & -6.9458 & 0 & -0.8392 & 0.138 & -6.0811 & 0 \\
\hline$F_{3}$ & 0.6259 & 0.1304 & 4.7992 & 0 & 0.3782 & 0.1168 & 6.4345 & 0 \\
\hline$\rho / \lambda$ & 0.6077 & 0.1055 & 5.7583 & 0 & 0.7518 & 0.1283 & 5.632 & 0 \\
\hline Test & $\begin{array}{c}\text { Degrees of } \\
\text { freedom }\end{array}$ & Statistics & & $\mathrm{P}$ values & $\begin{array}{c}\text { Degrees of } \\
\text { freedom }\end{array}$ & Statistics & & $\mathrm{P}$ values \\
\hline$R^{2}$ & & 0.7835 & & & & 0.7589 & & \\
\hline $\log \mathrm{L}$ & & -21.4025 & & & & -24.2542 & & \\
\hline LR & 1 & 11.5267 & & 0.0007 & 1 & 5.8208 & & 0.0158 \\
\hline AIC & & 52.8026 & & & & 56.5085 & & \\
\hline SC & & 59.9726 & & & & 62.2466 & & \\
\hline
\end{tabular}

$$
\begin{aligned}
& -0.83662 X_{9}-0.74982 X_{10}-0.64833 X_{11} \\
& +0.6259 X_{12}
\end{aligned}
$$

It can be seen from Table 7 that the spatial correlation coefficient $\rho$ in FSLM and $\lambda$ in FSEM passed the test with the significance level of 0.01 . It indicates that the divorce rate in China has a strong spatial correlation, and the divorce rate in the neighboring province affects the divorce rate in the province to a certain extent, and there is a significant spatial effect of the divorce rate in China.

4.2.3. Residual Normality and Randomness Test. The data of 12 explanatory variables observed in 2010 are introduced into formula (10), and the estimated divorce rate $(\mathrm{Y})$ is obtained. The residual test of regression model can be carried out by the actual and estimated divorce rates in 2010. First of all, from the residuals plot (Figure 2(a)), we can find that the residuals fluctuate near 0 , there is no obvious trend, and the residuals QQ plot (Figure 2(b)) revolves around the line and is concentrated at point $(0,0)$. Then, according to the ShapiroWilk normality test result (confidence level is 0 . 05), the $\mathrm{p}$ value is 0.2941 , greater than 0.05 . The original assumption that the residuals are normal distribution is accepted, and the residuals are obedient to normal distribution.

We have discussed the residuals compliance normal distribution, so we can test the randomness of the residuals, and here we use Mood's proposed run-test method to test the randomness of residuals. Here we use the mean method to determine the number of runs; that is to say, when the residual value is greater than or equal to the mean residual value, the number of runs is 1 , and when it is less than the mean value, it is 0 . At the confidence level is 0.05 , the p-value of run test is 0.598 , which is greater than 0.05 ; the original assumption that the residuals are random is accepted. 

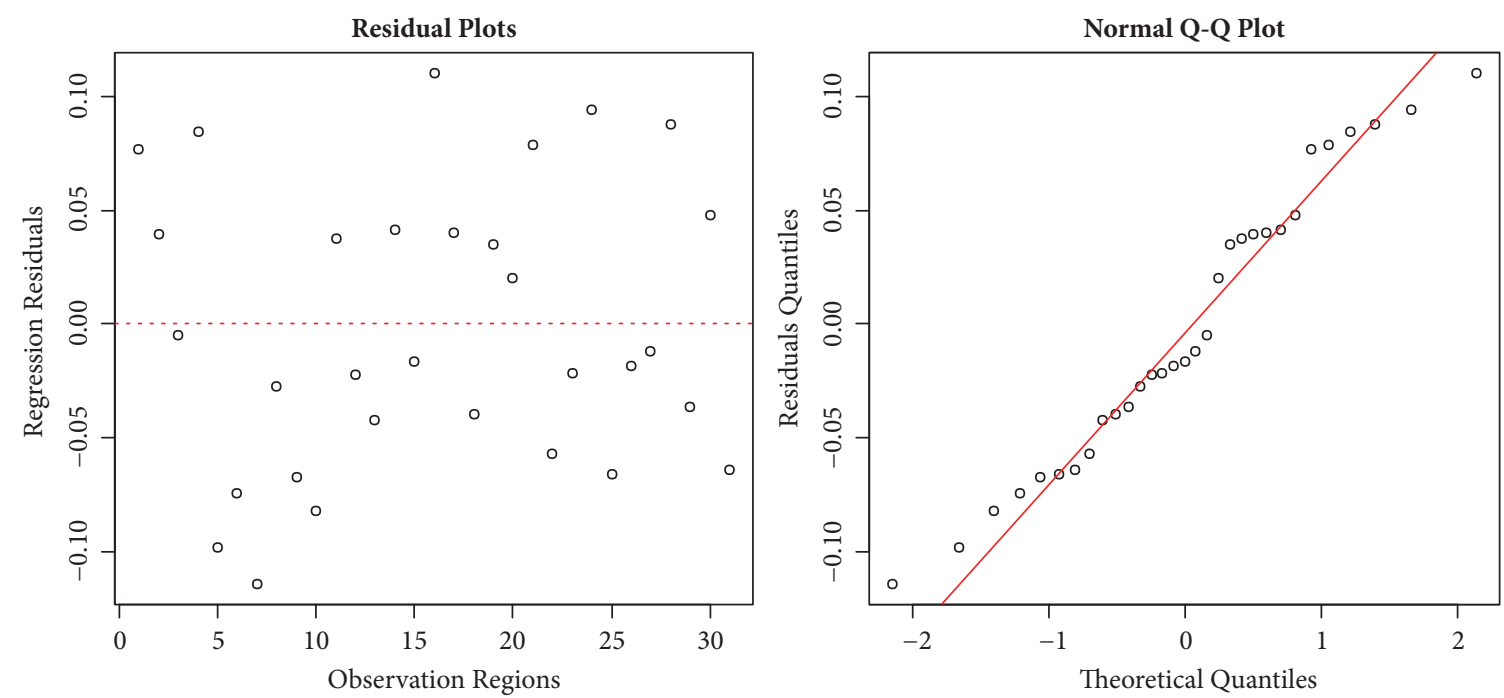

FIGURE 2: Residual test diagram, (a) the residual plots, and (b) the normal QQ plot of regression residuals.

TABLE 8: The comparison between OLS regression and spatial regression.

\begin{tabular}{|c|c|c|c|c|c|c|}
\hline & \multicolumn{2}{|c|}{ OLS estimates } & \multicolumn{2}{|c|}{ FSLM } & \multicolumn{2}{|c|}{ FSEM } \\
\hline & $\begin{array}{l}\text { Regression } \\
\text { coefficient }\end{array}$ & $P$ value & $\begin{array}{l}\text { Regression } \\
\text { coefficient }\end{array}$ & $P$ value & $\begin{array}{l}\text { Regression } \\
\text { coefficient }\end{array}$ & $P$ value \\
\hline Constant & 8.39E-06 & 1 & 0.0477 & 0.5617 & 0.1139 & 0.7464 \\
\hline$F_{1}$ & 0.2282 & 0.0549 & 0.1798 & 0.033 & 0.2437 & 0.0173 \\
\hline$F_{2}$ & -1.1814 & 0 & -0.9591 & 0 & -0.8392 & 0 \\
\hline$F_{3}$ & 0.827 & 0.0001 & 0.6259 & 0 & 0.3782 & 0 \\
\hline Test & Statics & & Statics & & Statics & \\
\hline Adjusted $R^{2}$ & 0.6121 & & 0.7835 & & 0.7589 & \\
\hline AIC & 62.3293 & & 52.8026 & & 56.5085 & \\
\hline SC & 68.0653 & & 59.9726 & & 62.2466 & \\
\hline
\end{tabular}

4.3. Comparative Analysis. In order to make a more intuitive comparison, the coefficients $\mathrm{R}^{2}$, SIC, and SC of the two models are compared (shown in Table 8).

4.3.1. From Table 8, the regression coefficient of the three factors shows that there is a significant positive correlation between divorce rate and social influence and minority customs, which has a significant negative correlation with family cohesion.

4.3.2. Based on the factor score function of social influence $\left(\mathrm{F}_{1}\right)$ in formula $(5)$, we can see that the tertiary industry share of GDP $\left(\mathrm{X}_{1}\right)$ is 0.917 , indicating that the influence is particularly obvious. In the expression of space lag model (10), the coefficient of the tertiary industry share of GDP. $\left(\mathrm{X}_{1}\right)$ is only -0.02215 , which is not only small, but also has a negative influence on the divorce rate. The main reason is that the negative influence of family cohesion $\left(\mathrm{F}_{2}\right)$ in spatial regression is too large, which leads to the influence of the tertiary industry share of GDP $\left(\mathrm{X}_{1}\right)$ in all variablesand then becomes smaller.
4.3.3. It can be seen from the factor score function of family cohesion and $(10)$ that the illiteracy rate $\left(X_{7}\right)$, the birth rate $\left(\mathrm{X}_{8}\right)$, and the family population quantity $\left(\mathrm{X}_{9}\right)$ have a large negative influence on the divorce rate. In the factor scoring function, it is known that the negative influence of illiteracy rate is the strongest, which indicates that the higher the proportion of higher education population, the higher the divorce rate.

4.3.4. The optimal factor $\mathrm{F}_{3}$ coefficient of the FSLM in Table 8 is 0.6259 , indicating that the minority customs have a significant impact on the divorce rate. That is reflected in the areas with more minority populations, where the divorce rate is significantly higher.

4.3.5. From comparing the adjusted $\mathrm{R}^{2}$, AIC, and SC, spatial regression model is superior to the ordinary least-squares regression model, and FSLM can better explain the space effect of the divorce rate in China. And the absolute value of the ordinary least squares regression coefficient is obviously less than the absolute value of the space regression coefficient. 
TABLE 9: The four stages of Chinese fertility policies.

\begin{tabular}{lcccc}
\hline $\begin{array}{l}\text { The fertility } \\
\text { policy }\end{array}$ & $\begin{array}{c}\text { Family Planning } \\
\text { Policy }\end{array}$ & $\begin{array}{c}\text { Two-child policy } \\
\text { (Couples are only children) }\end{array}$ & $\begin{array}{c}\text { Two-child policy } \\
\text { (One of couples is only children) }\end{array}$ & $\begin{array}{c}\text { Comprehensive } \\
\text { two-child policy }\end{array}$ \\
\hline Time stage & $1980-2001$ & $2002-2013$ & $2014-2015$ & $2016-$ \\
\hline
\end{tabular}

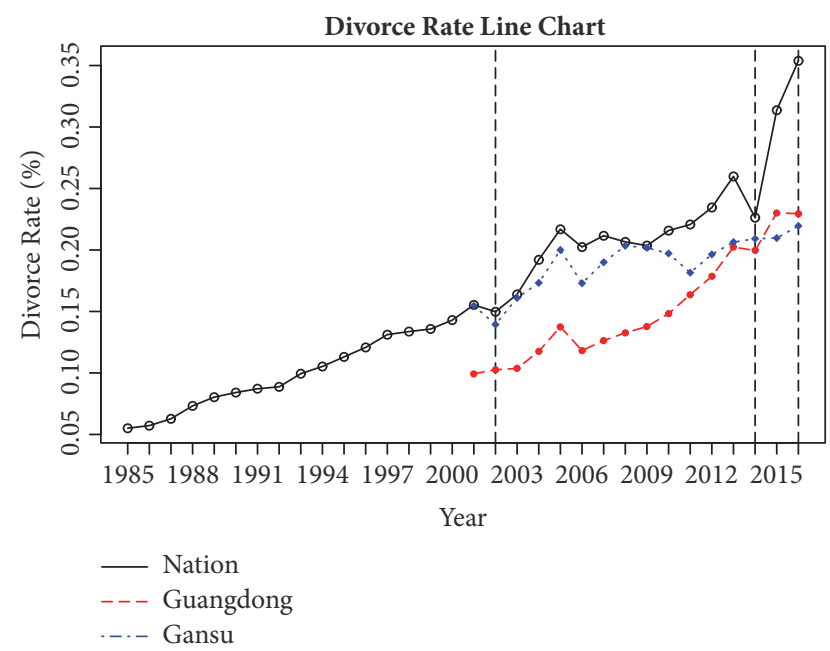

FIgURE 3: Divorce rate line chart.

4.4. Impact of Chinese Fertility Policies. The implementation of Chinese comprehensive two-child policy in 2016 has attracted people's attention, which will have a great impact on Chinese birth rate, mortality rate, and demographic structure. At the same time, another topic worthy of study is the effect of Chinese fertility policies on divorce rate, which does not seem to have much relevance on the surface. In fact, all previous adjustments in Chinese fertility policies will have negative impact on the divorce rate at that time. That is, when the Chinese government changes its fertility policies, the divorce rate in China will decline or the rate of divorce growth will slow down in that year, and similar situations will occur in various regions of China. Table 9 shows the four stages of Chinese fertility policies from 1980 to the present.

Two-child policy (couples are only children) means that if both husband and wife are only children, then they can have a second child and also (one of them is and only child) if one of them is an only child, then they can have a second child.

According to the national divorce rate data (1985-2016) from the China Statistical Yearbook and the divorce rate data from two randomly selected regions of China (Guangdong Province and Gansu Province (2001-2016)), the divorce rate data in different regions in China Statistical Yearbook began in 2001 , and the national data began in 1985 , so the data amount is not equal, but there is no problem to make a simple analysis. We draw a broken line chart of divorce rates in China from 1985 to 2016 and in Guangdong and Gansu provinces from 2001 to 2016. See Figure 3. We can clearly see that the trend of divorce rates in Guangdong and Gansu provinces is the same as that in the whole country, showing an overall upward trend.
In combination with Table 9, we find that when China implemented the two-child policy (couples are only children) in 2002, the divorce rate in China declined in that year. In 2001, the divorce rate in China was $0.15534 \%$, and in 2002 it was $0.14975 \%$. The same situation occurred in Guangdong Province and Gansu Province. When China adopted the twochild policy (one of the parents is an only child) in 2014, a similar situation occurred in 2002, the divorce rate of China was $0.25986 \%$ in 2013 and $0.22631 \%$ in 2014 . In 2016, when China implemented the comprehensive two-child policy, the growth rate of divorce in that year slowed down significantly as shown in Figure 3. Based on the above description, we can simply analyze that the fertility policies of China have a negative impact on divorce rate; thanks to the policy factor, they are not a general measurable variable, so we do not consider this factor in depth here.

\section{Conclusions and Recommendations}

5.1. Through the empirical results of the ordinary least squares regression model and spatial regression model, it can be seen that the divorce rate has a significant correlation with family cohesion, social influence, and minority customs, and the following conclusions are drawn.

5.1.1. Make the common factor extracted from the proportion of the urban population $\left(\mathrm{X}_{6}\right)$ and the per capita gross domestic product $\left(\mathrm{X}_{4}\right)$ and so forth as the social influence. In particular, the coefficient of the tertiary industry shares of GDP $\left(\mathrm{X}_{1}\right)$ has a significant impact on the rise in divorce rate. The result is in line with the current situation of China. With the speeding up of urbanization progress, the personal economic independence, frequent occupational mobility, and so forth will weaken the social influence, reduce social constraints on personal, and accelerate the broken process of marriage relationship. Eventually that will lead to divorce.

5.1.2. Make the common factor extracted from birth rate as the family cohesion, w2hich has a negative effect on the rise in divorce rates. It confirms the centralization of family structure and the rise in birth rate, which will strengthen the family's sense of responsibility and enlarge the bond of marital breakdown. It also reflects the different age composition of our country and the load of children and old people in each family, which is the fetter of marriage breakdown. This conclusion is consistent with the relatively low divorce rate reported in Guangdong and other regions, indicating that the policy of opening a two-child policy and expanding the family population will help to reduce the divorce rate.

5.1.3. Minority customs have a significant impact on the divorce rate, and the greater the proportion of ethnic 
minorities, the higher the divorce rate. Although ethnic factors only have a single index, it can also reflect the fact that the divorce rate is high in minority areas. The ethnic minority areas are characterized by slow modernization, low rates of education, low population mobility, and large family population, which will result in large family cohesion, and the divorce rate of most ethnic minority areas is higher than that of Han nationality.

5.1.4. After introducing the spatial correlation effect of divorce rate into regression model, the estimation value of the model has changed greatly. The absolute value of the explanatory variable coefficient is reduced, which means that the explanatory variable coefficient in the ordinary least-squares regression model is likely to be overestimated. Therefore, the factor spatial lag model is better when dealing with the regional divorce rate with spatial correlation. This also indicates that the spatial regression model is used to analyze the influence factors of divorce rate in Chinese provinces and the spatial interaction effect of the divorce rate in each province, and it is a good application innovation in terms of both research methods and results.

5.2. Based on the analysis of this paper, the following suggestions are proposed.

5.2.1. Strengthen social influence, improve the employment rate of talents, and reduce the mobility of population. From the empirical analysis, it can be seen that the divorce rate in China is obviously affected and increasing by social factors such as rising economic level, increasing population mobility, and accelerating urbanization. It also reflects the fact that the social cohesion has been reduced in the last few decades because of economic development, social diversity, and population movement. Relevant departments should take corresponding measures to reduce the negative impact of social factors on marriage.

5.2.2. Strengthen family responsibility education. As can be seen from the empirical analysis, family factors have a significant impact on the divorce rate. As the number of families, birth rate, old age, and child support rate rise, there is a negative effect on the divorce rate. In 2016, our country fully opened the two-child policy, which is beneficial not only to promote the sustained and healthy development of economy, but also to optimize the population structure. It can better satisfy the will of the masses, promote the happiness and harmony of the family, suppress the imbalance between the sexes, and alleviate the aging of the population. More importantly, the policy of opening a two-child policy can help reduce the divorce rate.

5.2.3. Strengthen the marriage legal system education of ethnic minority settlement and form a social atmosphere to reduce the divorce rate through various publicity channels. The minority customs in the empirical analysis also have a significant impact on the rising divorce rate in China. Some ethnic minorities have weak legal concept of marriage, and the concept of marriage is open and free, which will also affect the divorce rate in this area.

\section{Data Availability}

The data used to support the findings of this study are available from the corresponding author upon request.

\section{Conflicts of Interest}

The authors declare that there are no conflicts of interest regarding the publication of this paper.

\section{Acknowledgments}

This paper is supported by Chongqing Social Science Planning Project (Project no. 2016PY38).

\section{References}

[1] X. Anqi, "The Present Situation and Trend of Urban Marriage in China," Sociological Research, vol. 3, pp. 12-18, 1991.

[2] F. U. Hong-mei and L. I. Xiang-mei, "The Analysis of the Contemporary Chinese Divorce Situation and the Marriage Forecast," Northwest Population Journal, vol. 29, no. 2, pp. 5558, 2008.

[3] X. Yinlan, "The analysis of the social cost of the rising divorce rate," Gansu Social Sciences, vol. 29, no. 2, pp. 55-58, 2008.

[4] S. Liyun, L. Yang, and Xiangwu. P., "Spatial aggregation and spatial-temporal pattern of provincial divorce Rate in China," Population Research, vol. 6, pp. 74-84, 2015.

[5] K. D. Breault and A. J. Kposowa, "Explaining divorce in the United States: a study of counties, 1980," Journal of Marriage \& the Family, vol. 49, no. 3, pp. 549-558, 1987.

[6] P. A. Nakonezny, J. L. Rodgers, and R. D. Shull, “The Effect of No-Fault Divorce Law on the Divorce Rate Across the 50 States and Its Relation to Income, Education, and Religiosity," Journal of Marriage Family, vol. 57, no. 2, pp. 477-488, 1995.

[7] P. C. Glick and S.-L. Lin, "Recent Changes in Divorce and Remarriage," Journal of Marriage \& Family, vol. 48, no. 4, pp. 737-747, 1986.

[8] T. Katherine and S. South, "Structural determinants of the divorce rate:across-societal analysis," Journal of Marriage \& the Family, vol. 51, no. 2, pp. 391-404, 1989.

[9] Z. Junrong, "Economy and marriage: empirical analysis of divorce rate in 10 provinces and cities," Legal System and Society, vol. 8, article 358, 2008.

[10] X. Anqi and Y. Wenzhen, "The analysis of regional differences in divorce rate in China," Population Research, vol. 26, pp. 28-35, 2002.

[11] G. Mengtao, "Rural divorce rate and outdoor employment: research on village panel data from 2003 to 2009 in China," The Journal of World Economy, vol. 10, pp. 55-69, 2011.

[12] X. Anqi and M. Yongfu, "Analysis on the Characteristics and Causes of High Divorce Rate in Uygur Inhabited Rreas of Xinjiang," Population Science of China, vol. 2, pp. 25-35, 2001.

[13] H. Liu and L.-x. Yang, "Spatial Heterogeneity of Imbalanced Sex Ratio at Birth in Rural China and Its Influence Factors: Based on Geographically Weighted Regression Model," Population Journal, vol. 36, no. 4, pp. 5-15, 2014.

[14] Y.-f. Tan and Y.-m. Zeng, "Spatial-temporal Pattern Analysis and Spatial Disparity Research on Provincial Transition of Mechanisms in Stabilizing Low Fertility in China," Population Journal, vol. 36, no. 2, pp. 5-18, 2014. 
[15] L. Anselin, Spatial Econometrics: Methods and Models, Boston Kluwer Academic Publishers, 1988.

[16] L. Anselin, A. K. Bera, R. Florax, and M. J. Yoon, "Simple diagnostic tests for spatial dependence," Regional Science \& Urban Economics, vol. 26, no. 95, pp. 77-104, 1996.

[17] S. S. Shapiro and M. B. Wilk, "An analysis of variance test for normality: Complete samples," Biometrika, vol. 52, no. 3/4, pp. 591-611, 1965.

[18] J. Li, "Semiparametric residuals and analysis for a scleroderma clinical trial," Communications in Statistics-Theory and Methods, vol. 38, no. 18, pp. 3339-3350, 2008.

[19] "National Bureau of Statistics of the People's Republic of China data (2004-2014)[J/OL]," http://data.stats.gov.cn/search.htm?

[20] W. Shengxi, "Rational calculation and economic analysis of divorce rate," hina Urban Economy, vol. 17, pp. 196-198, 2011. 


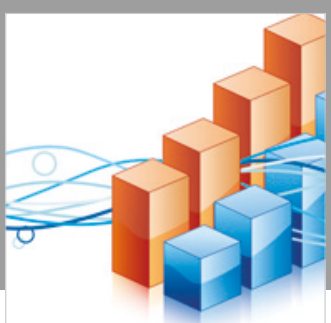

Advances in

Operations Research

\section{-n-m}
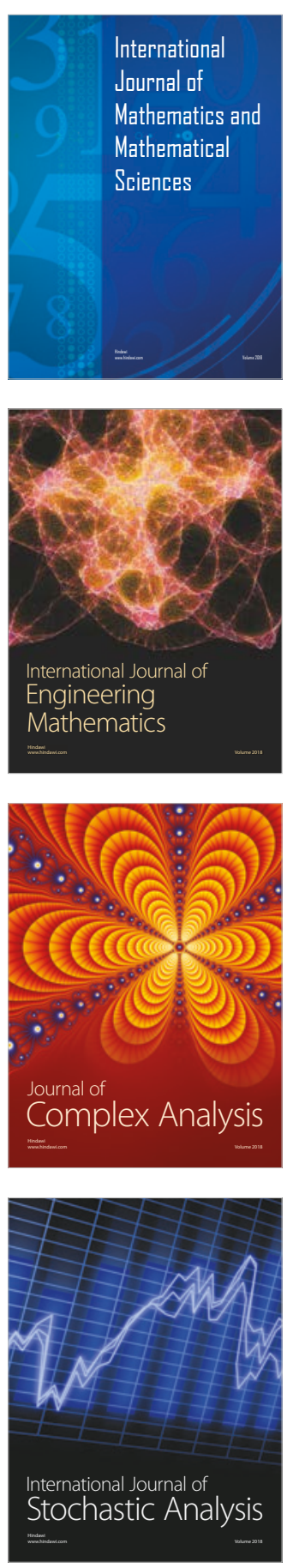
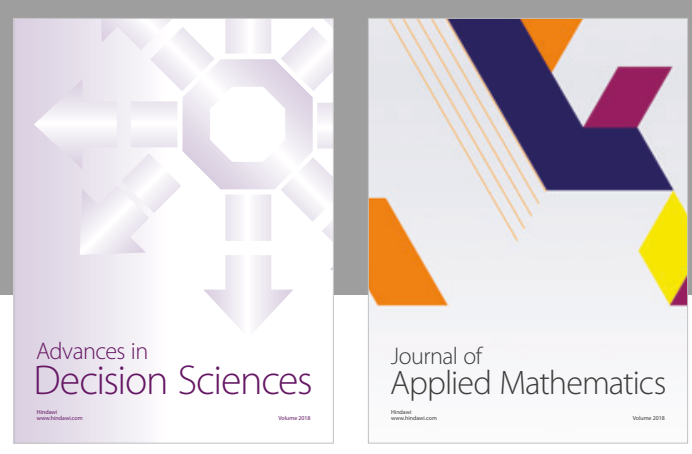

Journal of

Applied Mathematics
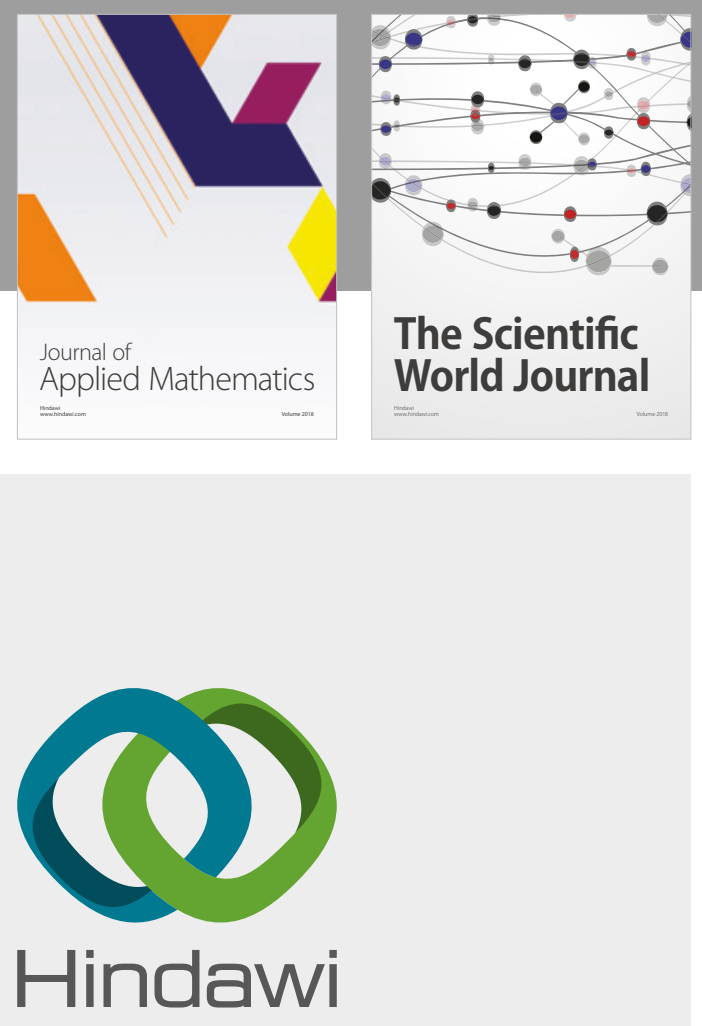

Submit your manuscripts at

www.hindawi.com

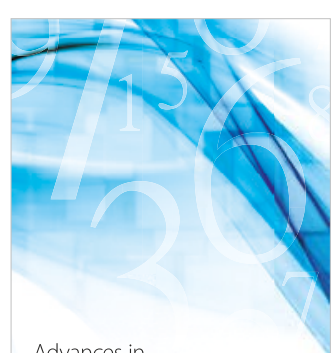

Advances in
Numerical Analysis
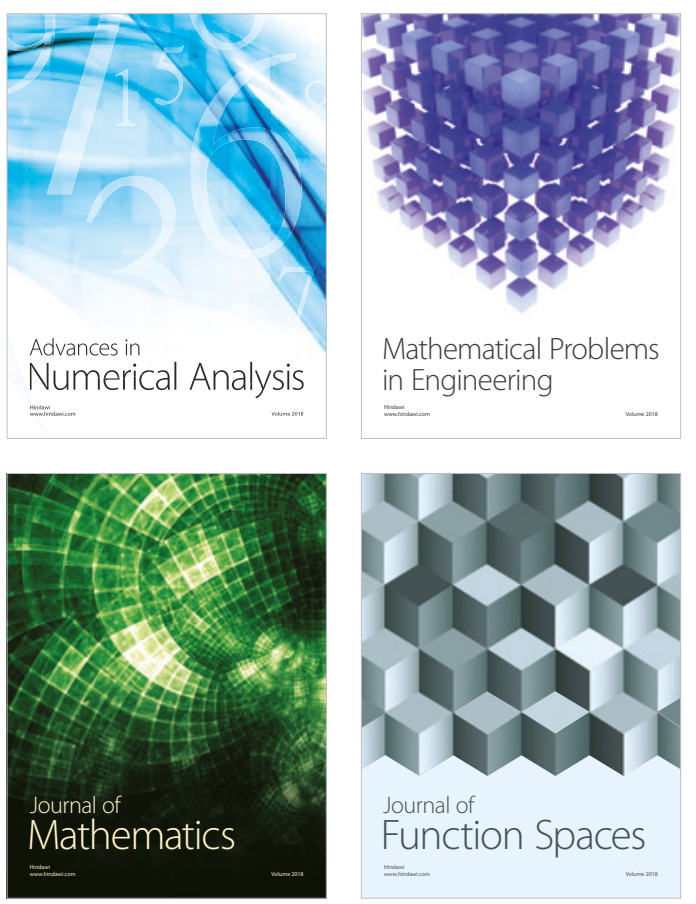

Mathematical Problems in Engineering

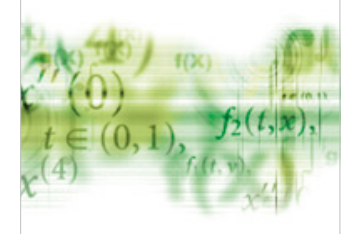

International Journal of

Differential Equations

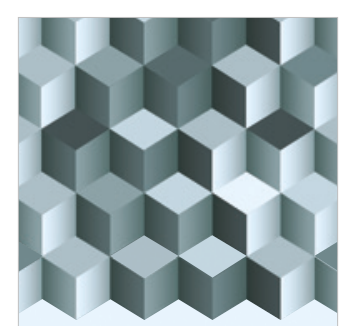

Journal of

Function Spaces

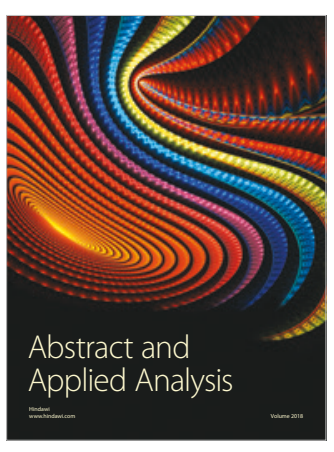

The Scientific

World Journal

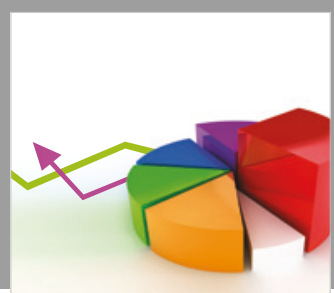

Journal of

Probability and Statistics
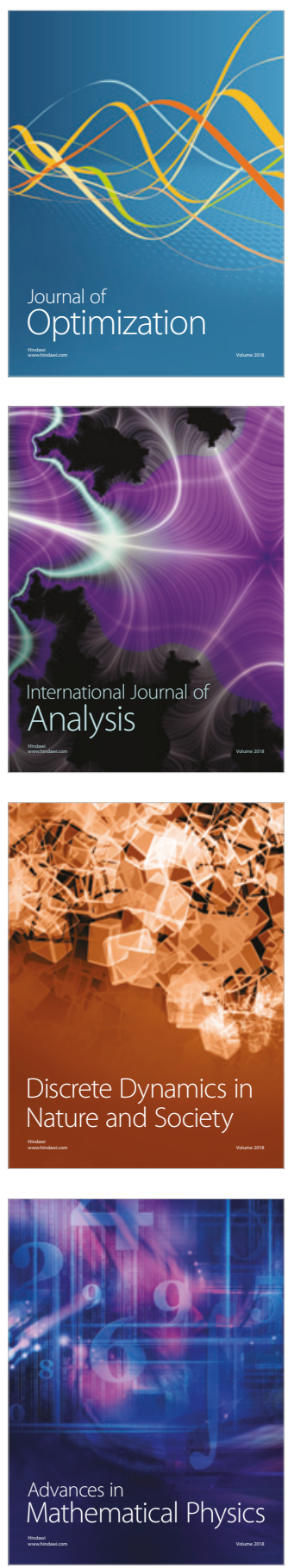